\title{
Episodes of interferences of War and Math in the Life and Work of Werner Fenchel
}

Episódios de interferências da Guerra e da Matemática na vida e na obra de Werner Fenchel

Tinne Hoff Kjeldsen ${ }^{1}$

\section{Resumo}

No presente artigo, estudamos episódios da vida e obra do matemático alemãodinamarquês Werner Fenchel na perspectiva da importância da Segunda Guerra Mundial. Por um lado, veremos como a sociedade matemática, em particular o matemático Harald Bohr, ajudou Fenchel a estabelecer uma vida acadêmica em Copenhague, na Dinamarca. Por outro lado, veremos como a organização da contribuição do cientista para o esforço de guerra nos EUA durante a guerra e o financiamento militar pós-guerra da pesquisa acadêmica no período pós-guerra interferiu em alguns dos trabalhos matemáticos de Fenchel, especialmente em sua contribuição para a teoria da dualidade na programação não linear. Como tal, o estudo apresentado neste artigo contribui para nossa compreensão de como a matemática e as condições de um determinado local e tempo interferem na história da matemática.

Keywords: Funções conjugadas convexas; dualidade de Fenchel; história da programação matemática; Abordagem da história da matemática de múltiplas perspectivas.

\section{Abstract}

In the present paper we study episodes of the life and work of the German-Danish mathematician Werner Fenchel from the perspective of the significance of the Second World War. On the one hand, we will see how the mathematical society, in particularly the mathematician Harald Bohr, helped Fenchel to set up an academic life in Copenhagen, Denmark. On the other hand, we will see how the organisation of scientists' contribution to the war effort in the USA during the war, and the post war military financing of academic research in the post war period interfered with some of Fenchel's mathematical work, especially his contribution to duality theory in nonlinear programming. As such, the study presented is this paper contributes to our understanding of how mathematics and conditions of a particular place and time interfere in the history of mathematics.

Keywords: Conjugate convex functions, Fenchel duality, History of mathematical programming, Multiple perspektive approach to history of mathematics.

\footnotetext{
${ }^{1}$ University of Copenhagen | thk@math.ku.dk
} 


\section{Introduction}

As with all human activities, mathematicians' work with mathematics is conditioned by time and place. It is situated in a historical, social and scientific context. A mathematician's development of mathematics is contingent on the past, the mathematics that is already there and known to the mathematician, the "trend" of mathematics in that particular place and time in which a mathematician is working, her or his motivation, ambition, expectations for the future being for personal development or for mathematics, as well as life circumstances in general.

For history of mathematics, to explore how time and mathematics interfere in such a setting means to pay attention to the historical actors, their motivations, and intended and unintended consequences of their actions. It is an action-oriented conception of history where people, their projects and their actions are taken as point of departure for historical investigations. This is an open approach to history of mathematics where historical investigations are attached to concrete projects of past mathematicians, studied from various perspectives.

Such a "multiple perspective approach to history of mathematics" is an open approach in the sense that the results or insights of historical studies depend on the perspective - the point of view - from which the historical episode in question is studied. ${ }^{2}$ The historical episodes presented in this paper has been studied from a war perspective: 1) the significance of the mathematical community in the life of Werner Fenchel in connection with the Nazi regime in Germany, and 2) conditions provided by the military-university complex in the USA in the post war period for an episode of his mathematical research. ${ }^{3}$

\section{Werner Fenchel, two times a refugee due to World War II}

Moritz Werner Fenchel (1905-1988) was one of the Jewish Göttingen mathematicians whom the Danish mathematician Harald Bohr (1887-1951) helped escape from Germany and set up life elsewhere after the Nazi regime came into power.

Fenchel was born in Berlin where he also grew up. He graduated from high school in the fall of 1923 and continued his education at the University of Berlin (FENCHEL 1975. p. 1). As he phrased it in a seminar, he gave at the Danish Mathematical Society with the title "Memories from my study time" when he turned 70, it might seem strange for someone interested in mathematics not to go to Göttingen. This, however, as he explained, was on the first hand not an option for financial reasons, and on the other hand, he had become more and more interested in physics during his early teenage years, and physics was very

\footnotetext{
2 For a more detailed introduction to a Multiple perspective approach to history of mathematics, see Kjeldsen (2019). The approach is also introduced in Kjeldsen (2012) in discussions of uses of history of mathematics for learning and teaching of and about mathematics. I have borrowed the term "multiple perspective" from the historian Bernard Eric Jensens's (2003) term "en flerperspektivisk tilgang" from his book "historie-livsverden og fag" (History-lifeworld and discipline) and adapted it to history of mathematics.

${ }^{3}$ The investigations are, among others, based on archival material from the Werner Fenchel papers at the Archive at the Department for Mathematical Sciences, University of Copenhagen, Denmark http://web.math.ku.dk/arkivet/fenchel/wfenpapr.htm.
} 
well represented at a high level in Berlin with the Nobel Laureates Max Planck and Albert Einstein among others (FENCHEL 1975).

Along the way, though, his interest in physics led him to mathematics. In an interview conducted the $19^{\text {th }}$ of August 1986 on behalf of the Royal Danish Academy of Sciences and Letters (FENCHEL 1986) he explained how he tried to read some more advanced books on relativity theory and realized that he needed to understand the mathematics. After a couple of semesters at the university, his main interest had shifted to mathematics.

He was a student in Berlin from 1923 to 1928. Both in the interview and in his seminar where he shared his recollections from his time as a student in Berlin, he describes a dichotomy between the thriving of academic work and the miserable conditions in general in Germany:

\begin{abstract}
The external conditions at this time were anything but nice. Germany was still suffering from the consequences of the First World War. The inflation was at its highest [...]. The political oppositions were very strong. (FENCHEL 1975, p. 1).

In spite of the miserable conditions, there was a very flourishing life for science in general in Germany at the time. Strangely enough. The conditions were miserable. The students had almost nothing ... (FENCHEL 1986, p. 2)
\end{abstract}

One of the things he emphasized in particular from his student time is a special organization among the mathematics and physics students. Some of the students in the mathematics and physics program who had participated in World War I and remembered the miserable conditions for in particular students in the beginning of their studies, decided to set up an association for all mathematics and physics students. Besides giving the students a voice in the group of professors and the administration, its purpose was to establish a forum where students could help each other. It was called Mapha (Mathematisch-physikalische Arbeitsgemeinschaft). They managed to gain the trust of the professors and Mapha representatives participated in the meetings where the mathematics professors planned the next semester's teaching in mathematics. Mapha organized introductions to the studies for first year students, they made books and writing materials available for the students at a low price, they arranged so-called "work circles", called "work circus" where challenging material from the lectures was discussed among the students with an older student in charge. Also social events were on the Mapha agenda: music evenings, Christmas parties and Sunday outings (FENCHEL 1975, p. 3-6).

Fenchel graduated from the University of Berlin in 1928 with a thesis on closed space curves in differential geometry. He then went to Göttingen where he was Edmund Landau's assistant - a rather time-consuming job. In the interview (FENCHEL 1986, p. 3), he describes how he had to sit in on all Landau's lectures and react immediately if he made a mistake, go through all his mail together with Landau and write answers, read through and discuss word by word the manuscript for the lectures Landau were preparing, and likewise with Landaus mathematical work. Apparently, Richard Courant (1888-1972) and Otto E. Neugebauer (1899-1990) thought he needed some time off and arranged for him to get a Rockefeller scholarship in the year 1930/1931 (FENCHEL 1986, p. 3).

Fenchel went first to Italy to study differential geometry with Tullio Levi-Civita (18731941), and then to Copenhagen in March 1931. Fenchel's connection to Danish mathematicians dated back to 1929 when Fenchel met Harald Bohr who was visiting the 
institute in Göttingen. In Copenhagen, Fenchel established closed contact with other Danish mathematicians, Jakob Nielsen (1890-1959) and Børge Jessen (1907-1993). This was also the period where he became acquainted with Tommy Bonnesen (1873-1935). According to Fenchel, Neugebauer suggested that Fenchel and Bonnesen should write something together on convexity. This led to the very influential book Theorie der konvexen Körper, which is now considered a classic in convexity theory. Fenchel describes their collaboration in the interview):

In a way, we complemented each other well. I had undertaken to review the literature at the excellent library in Göttingen. In the spring of 1932, I returned to Copenhagen during the German spring break, and then we started writing. We split the substance between us. Later in 1932, Bonnesen came to Göttingen. And then came the Nazi era ... (FENCHEL 1986, p. 4)

The Nazi regime came into power in the beginning of 1933 and they immediately began to implement their ideology. In a letter to Børge Jessen dated $13^{\text {th }}$ of March, Fenchel expressed a kind of reassurance that the situation would calm down and that it would not affect university life:

With us, of course - especially before the elections - the political tumult has also spread somewhat to university life. But the stability of the situation will soon have a calming effect. It can be assumed that our scientific work opportunities will not be affected by the political upheaval (quoted from Ramskov (1995, p. 310), my translation from German into English.)

However, only a month later, on the $13^{\text {th }}$ of April, the first academics were removed from service and on the $26^{\text {th }}$ Richard Courant and Emmy Noether (1882-1935) among others realized through the local press that they were exempt from service from Göttingen University. Courant took contact to Harald Bohr who immediately invited him to Copenhagen so they could discuss the situation and some mathematical issues. (RAMSKOV, 1995, p. 313). Bohr did a lot of work to help mathematicians who had been exempt from service in Germany get jobs in other countries. Herbert Busemann (1905-1994) and Fenchel from Göttingen both came to Copenhagen in 1933 (RAMSKOV 1995, p. 314-315).

Being a Jew, Fenchel was dismissed from Göttingen in the spring of 1933, and in May Bohr was able to invite him to come to Copenhagen. Käte Sperling, who was also a mathematician and had been studying together with Fenchel in Germany, came to Copenhagen in December that year. They married right away (FENCHEL 1986, p. 4). In the beginning, there was no job for Fenchel at the University of Copenhagen. In the interview, Fenchel describes how he remembered it:

Harald Bohr raised some money and then Neugebauer came here at the end of the year. Already in Göttingen, I had helped him with the editorial work on Zentralblatt für Mathematik. He got the publisher's, Springer's, permission to move the editorial work to Copenhagen. I then helped Neugebauer the years he was here, until 1938, [...] I made a little money on that, and in those years, I also translated Jacob Nielsen's book "Mechanics" into German. I thought it was a fun task and then I learned mechanics that way. This is how we got by until 1937, when I was hired for the Polytechnic Teaching Preparatory Course (in mathematic). The job was a little unusual for me. One had to go through high school math in one year for a very mixed audience. (FENCHEL 1986, p. 4) 
Denmark was occupied by Germany April 9, 1940. In 1942, Fenchel applied for an associate professorship at the mathematics department at the University of Copenhagen. He was worried that the Germans would interfere, but they didn't it and he was employed as associate professor.

The action to deport Jews in Denmark to concentration camps was initiated on October 2, 1943. Information about the action was leaked, and around 7000 Jews made it to Sweden, including Werner and Käte Fenchel. Like others, they crossed over to Sweden in a small boat from Dragør, a small fishing village near Copenhagen Airport. When they arrived in Sweden, they were asked the next morning by the police if they had relatives or friends in Sweden. Fenchel knew the Hungarian mathematician Marcel Riesz (1886-1969) from Lund - and so did the police officer. He called Riesz who should have replied: "The beds are made". The Fenchels borrowed ten Swedish crowns from the police officer to get to Lund where they first stayed at the mathematics department at Lund's University and later in an apartment with other Danish refugees. Their son, Tom Fenchel who was born in 1940, however, was left behind in Denmark. Before they crossed over to Sweden, the Fenchels were told that children would not be taken on board. Tom went to Jutland in Denmark and lived there for a while until he also came to Sweden with the help of the Danish resistance movement. Both Werner and Käte Fenchel worked in Sweden. They taught mathematics at the Danish High School for refugees in Lund, and Werner Fenchel lectured at Lunds University. During their time in Sweden, Fenchel was still employed by the University of Copenhagen and still received his salary. In the catalogue over courses and lectures from the mathematics department, it was stated that Fenchel did not lecture in this semester. (FENCHEL (1986, p. 5), FENCHEL (1955)).

Fenchel returned to Denmark in 1945, and he kept his associate professorship at the university until 1947 when he was hired as a so-called "Docent" (something between associate and full professor) at the Polytechnic School. In 1951, he became full professor there, and in 1955, Thursday March 3, one could read in the Danish newspaper Berlingske Tidende that Fenchel would be "called"4 as full professor to the mathematics department at the University of Copenhagen.

\section{Fenchel in Princeton and the military-university complex in the USA}

Werner Fenchel was what is called a "pure" mathematician. In an interview (FENCHEL u.d.) in connection with his full professorship at the University of Copenhagen, with the heading Mennesket taaler ikke, at alt bliver opnaaet (Man cannot bear everything being achieved), he is quoted for having said about doing mathematics:

We do not have an eye towards the practical results at all. Often, something completely unforeseen practical comes out of it anyway. But the satisfaction of cultivating Mathematics as a Science is if anything

\footnotetext{
${ }^{4}$ To be "called" means that the professorship was not announced in an open call. As it was stated in the newpaper, this was a rare occasion.
} 
philosophical. And then one must be haunted by a burning curiosity. Ahead always beckons the truth you know you can never obtain. ${ }^{15}$

It is both a bit ironic and a kind of proof, an illustration, of his statement above that he himself became quite famous in one of the more applied fields of mathematics called nonlinear programming (or nonlinear optimization) for his duality concept, known as 'Fenchel duality'.

The reason for this was, as Fenchel's life path, also due to circumstances directly related to World War II - namely the university-military complex in the USA.

During the war, civilian scientists in the USA contributed to the war effort through contracts with the OSRD (Office of Scientific Research and Development) which was established in May 1941, financed directly by Congress, and headed by Vannevar Bush (1890-1974) (see e.g. ZACHARY, 1997). Two years later the Applied Mathematics Panel (AMP), which organized many of the mathematicians, was founded as a subsection under OSRD and headed by Warren Weaver (1894-1978) (Owens 1989). After the war, there was a concern about how to secure the further funding and growth in science in peacetime. There was a belief in the necessity to support basic research in science. The Navy established the Office of Naval Research (ONR) in 1946 and in the first four years, it became the main sponsor for research at the universities funded by the government. ${ }^{6}$ In an ONR report from 1949 one can read that:

... the huge university research program of the Navy Department is the greatest peacetime cooperative undertaking in history between the academic world and the government. This significant educational and scientific experiment now embraces approximately 1200 projects in about 200 institutions with a total expenditure of approximately $\$ 20,000,000$ a year. Nearly 3,000 scientists and 2,500 college and university graduate students are actively engaged in basic research projects in the many fields of vital interest to the Navy. (Cited in (SCHWEBER 1988, p. 17))

One of the projects that was funded by ONR was a logistic project that was run from the mathematics department at Princeton University by Albert W. Tucker (1905-1995). The project grew out of a logistic problem in the Air Force - to set up what they called a "program" for activities, a schedule so to speak. George B. Dantzig (1914-2005) and Marshall K. Wood described the Air Force programming problem in a paper published in 1949 as:

...the construction of a schedule of actions by means of which an economy, organization, or other complex of activities may move from one defined state to another or from a defined state toward some specifically defined objective. (DANTZIG AND WOOD 1949, p. 193-194)

The mathematical model was to optimize a linear function constrained by linear inequality constraints. It was soon to be named "a linear programming problem". Dantzig traveled to Princeton University to consult with John von Neumann (1903-1957) at the

\footnotetext{
5 "- De praktiske Resultater skeler vi overhovedet ikke til. Ofte kommer der alligevel noget helt uforudset praktisk ud af det. Men tilfredsstillelsen ved at dyrke Matematikken som Videnskab er snarest en filosofisk. Og saa maa man være besat af en brændende Nysgerrighed. Forude vinker altid den Sandhed, man ved, at man aldrig kan indhente."

${ }^{6}$ For literature on ONR see (Kjeldsen 2000, Old 1961, Sapolsky 1979, Rees 1977b, Schweber 1988).
} 
Institute for Advanced Study about how to solve the problem. Von Neumann who had written the book Theory of Games and Economic Behavior during the war together with Oskar Morgenstern (1902-1977) recognized the connection between the Air Force programming problem and two persons zero-sum games. Besides being a professor at the Institute for Advanced Studies, von Neumann also functioned as a consultant and as a member of various governmental advisory boards among others for the Air Force and for the mathematics division of ONR. The mathematician Mina Rees (1902-1997) who had been technical aid to Warren Weaver in the AMP during the war became the head of the ONR's mathematics division. She has given the following account of how she remembers the establishment of the logistic project in the ONR:

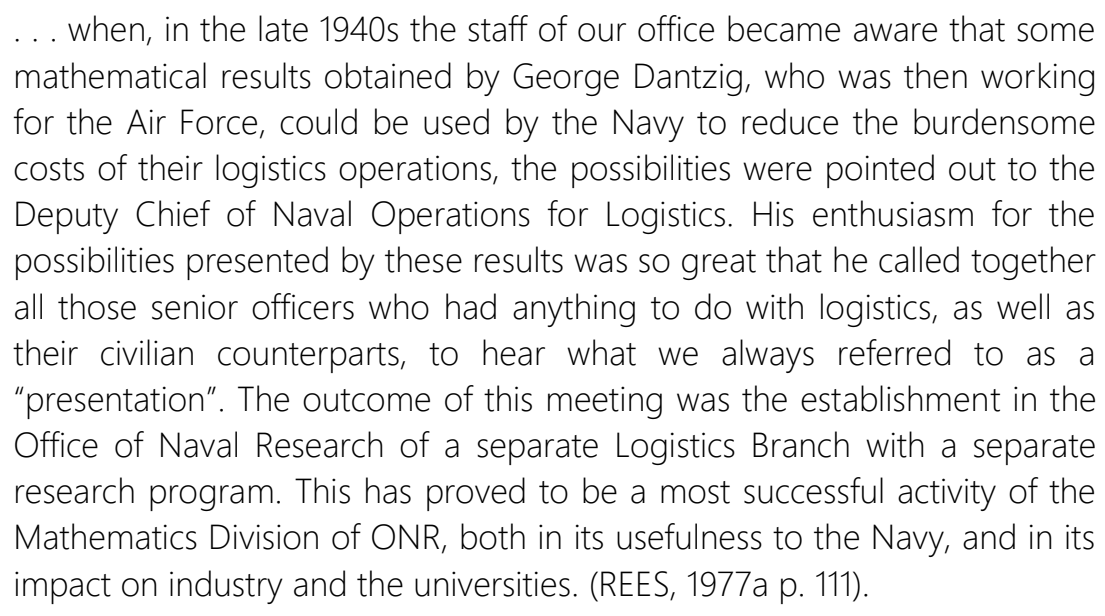

Dantzig met Tucker during one of his visits to Princeton to discuss with von Neumann the option of establishing a university-based project funded by the ONR. The outcome was, in the beginning, a summer trial project with Tucker as the principal investigator. The purpose of the project was to clarify the connection between linear programming and game theory and to investigate and further develop the mathematical foundation for linear programming.

The first group consisted of Tucker, Harold W. Kuhn (1925-2014) and David Gale (19212008). They presented their results at the first conference on linear programming, which was held in Chicago at the Cowles Commission in June 1949. These were later published in the conference proceedings Activity Analysis of Production and Allocation (Koopmans 1951). Tucker, Kuhn and Gale formulated and proved existence theorems for solutions of linear programming problems and the duality theorem - and related those to the theory of two persons zero-sum games.

The duality theory for linear programming is mathematically interesting and Kuhn and Tucker continued their collaboration, trying to extend the duality theorem for linear programming to the nonlinear case. Their paper, entitled Nonlinear Programming, was published in the proceedings of The Second Berkeley Symposium on Mathematical Statistics and Probability, which took place in 1950. They proved what rapidly became known as the Kuhn-Tucker (later renamed the Karush-Kuhn-Tucker) necessary conditions for optimality of a solution in nonlinear programming under some constraint qualification. ${ }^{7}$ The strategy, they

\footnotetext{
${ }^{7}$ For a discussion of Karush' contribution, see Kjeldsen (2000).
} 
used in the paper, was to investigate equivalence between a solution to a nonlinear programming problem and the saddle value problem for the corresponding Lagrange function. They did not come up with a duality result in their Nonlinear Programming paper, but they gave directions for further development of the theory in relation to convexity:

Throughout this paper it is assumed that the functions occurring are differentiable. But it seems to be an interesting consequence of the directional derivative properties of general convex (concave) functions [2, pp 18-21] that the equivalence between an inequality constrained maximum for $g(x)$ and a saddle value for the Lagrangian $\varphi(x, y)$ still holds when the assumption of differentiability is dropped. (KUHN and TUCKER 1951, p. 482)

This was the state of affair in 1950. At the same time, Fenchel was travelling around in the USA on sabbatical in 1950. In the interview, he explained how his sabbatical was extended due to an invitation from Tucker to contribute to the ONR project:

I was given a leave of absence and had to pay a substitute teacher but there was a little left. The Americans paid. At the University of Southern California, they paid me as a guest lecturer; modest, but you could live off it. Later I came to Stanford with $\$ 3$ in my pocket. Segal helped me right away. There I gave some lectures and talks; we attended the International Mathematics Congress at Cambridge Massachusetts. That is how Lars Gårding, whom I knew well from my time in Lund [Sweden], and his wife drove us around the US by car and to the East Coast. After the Congress, I had an invitation to the Institute for Advanced Study in Princeton, a scholarship for one semester. Afterwards, when my leave was over, I was invited by Tucker to give lectures at Princeton University. My leave was extended. (FENCHEL 1986, p. 6).

The reference, [2, p. 18-21], above in the quote from Kuhn and Tucker's Nonlinear Programming paper is to Bonnesen and Fenchel's monograph Theorie der konvexen Körper. Fenchel did not elaborate further about his connection to Tucker in the interview, but one can imagine that it must have been exiting for Tucker and his group that Fenchel was in Princeton. The lectures that Fenchel gave in Tucker's logistic project in Princeton was on convexity. They were written down based on notes taken by D. W. Blackett and printed in mimeographed form (FENCHEL 1953). They were never published, but they circulated and they had a huge influence on the further development of convexity theory, especially the Fenchel duality between convex functions. ${ }^{8}$ They became a standard reference work just like his book on convex bodies with Bonnesen.

Fenchel had not worked on optimization and he was not driven by applications and the usefulness of mathematics, as also evidenced by the quote above from the interview in the Danish newspaper. The year before, in 1949, he published a paper in which he was exploring the structure underneath certain inequalities that appear in mathematical analysis (FENCHEL

\footnotetext{
${ }^{8}$ Especially Ralph Tyrrell Rockafellar's work on convex analysis was inspired by Fenchel's lecture notes, see e.g. Rockafellar (1970). See also Kjeldsen (forthcoming): "From duality in mathematical programming to Fenchel duality and convex analysis: Duality as a force of inspiration in the creation of new mathematics", to be published by Birkhäuser in a book on duality in mathematical thinking, edited by Ralf Krömer, Emmylou Haffner and Klaus Volkert.
} 
1949). This led him to introduce what he called conjugate convex functions, and these came to play a central role, as we will see in the next section, for Fenchel's contribution to nonlinear programming.

From letters between Fenchel, Tucker and Kuhn and from Fenchel's lecture notes it is clear that Fenchel was introduced to the programming problem by Tucker while he was in Princeton and that he developed what became the first duality result for nonlinear programming in the course of the series of lectures he gave in Tucker's project - as he wrote in the "Acknowledgement" section of the lecture notes:

The author wishes to express his gratitude to Professor A. W. Tucker for giving him the opportunity to write this report and for calling his attention to the problems dealt with in the final sections (pp. 105-137) (FENCHEL 1953).

The final sections contain his duality theorem for nonlinear programming which, as we will see in the next section, was based on his notion of conjugate convex functions, a duality between convex functions, as he phrased it in the interview:

... the duality theory between convex functions was introduced in my article from '49 in the "Canadian Journal of Mathematics" and expanded in several ways in the notes [the lecture notes from Princeton]. (FENCHEL 1986, p. 6).

\section{Fenchel's contribution to nonlinear programming and his duality result}

The duality between convex functions that Fenchel mentioned in the interview as quoted above, is his notion of conjugacy, which he introduced in his paper On Conjugate Convex Functions from 1949 (FENCHEL 1949). He noticed that in several of the inequalities used in analysis "pairs of "conjugate" functions occur" (p. 73) and the purpose of his paper was to explain the general idea underneath this correspondence.

He considered a convex function $f\left(x_{1}, \ldots, x_{n}\right)$, defined in a convex set $G$ of $\mathbb{R}^{n}$ and satisfying some continuity conditions and such that $\lim _{x \rightarrow x^{*}} f(x)=\infty$ for each boundary point $x^{*} \notin G$. He looked at the set $\Gamma \in \mathbb{R}^{n}$ of all points $\xi=\left(\xi_{1}, \ldots, \xi_{n}\right)$ for which the expression

$$
\sum_{i=1}^{n} x_{i} \xi_{i}-f(x)
$$

is bounded from above in $G$. That $\Gamma$ is not empty follows from results from the theory of convexity about supporting hyperplanes. Fenchel then defined $\varphi$ as the least upper bound:

$$
\varphi(\xi)=\sup _{x \in G}\left(\sum_{i=1}^{n} x_{i} \xi_{i}-f(x)\right)
$$

Figure 1. For $f(x)=1 / 2 x^{2}, \varphi(2)=2$. 


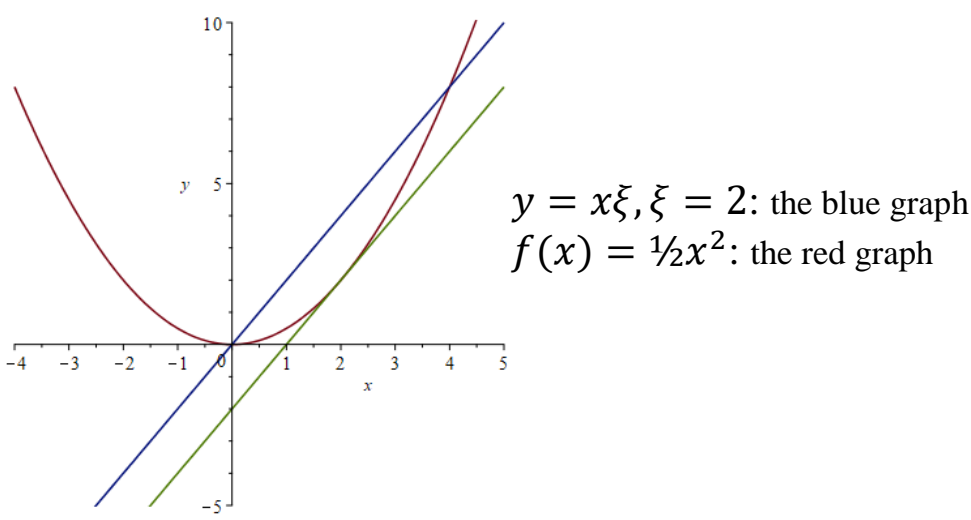

The green graph is a supporting hyperplane with $(2,2)$ as point of contact, and we see that $-\varphi(2)$ is the $y$-intercept of this hyperplane

From the construction and the existence of a supporting hyperplane through $\left(x^{0}, f\left(x^{0}\right)\right)$ for an arbitrary interior point $x^{0}$ of $G$, Fenchel argued that the inequality

$$
x_{1} \xi_{1}+\cdots+x_{n} \xi_{n} \leq f\left(x_{1}, \ldots, x_{n}\right)+\varphi\left(\xi_{1}, \ldots, \xi_{n}\right)
$$

holds for all $x=\left(x_{1}, \ldots, x_{n}\right)$ in $G$ and all $\xi=\left(\xi_{1}, \ldots, \xi_{n}\right)$ in $\Gamma$, and to every interior point of $G$ there corresponds at least one point $\xi$ of $\Gamma$ for which equality holds. He called the two functions $f$ and $\varphi$ conjugate. The correspondence between $G, f$ and $\Gamma, \varphi$ is symmetric and unique. If $H$ is a supporting hyperplane with normal vector $\left(\xi_{1}, \ldots, \xi_{n},-1\right)$ and if $x^{0}, f\left(x^{0}\right)$ is a point of contact, then

$$
\varphi(\xi)=\sum_{i=1}^{n} x_{i}^{0} \xi_{i}-f\left(x^{0}\right)
$$

and $-\varphi(\xi)$ is the $y$-intercept of this hyperplane (FENCHEL 1949, p. 73-75), see figure 1. As Fenchel explained in the paper, the two hypersurfaces $y=f(x)$ and $\eta=\varphi(\xi)$ correspond to each other in the polarity with respect to the paraboloid $2 y=\sum x^{2}$, since each of the hypersurfaces is the envelope of the polar hyperplanes of the points of the other (FENCHEL 1949, p. 77). This follows from the construction, since $y=f(x)$ can be considered as the envelope of the hyperplanes of the points of the other (FENCHEL 1949, p. 77). This follows from the construction, since $y=f(x)$ can be considered as the envelope of the hyperplanes where $\xi$ in $\Gamma$ is the parameter and the points $(\xi, \varphi(\xi))$ are the poles of these hyperplanes. Also, the conjugacy transformation of Fenchel is, as noted by Fenchel, a generalization of the Legendre transformation of the theory of differential equations. ${ }^{9}$

\footnotetext{
${ }^{9}$ For a discussion of naming, see Kiselman (2019) in which Kiselman presents an English translation of a letter from Fenchel to Kiselman dated March 7 1977. Kiselman had asked Fenchel about the many terms used in the history of duality in convexity theory. Fenchel wrote a long letter to Kiselman and in the end explained that he had used the term conjugate functions because he "considered the relation as a generalization of the "conjugated exponents" of classical analysis $x^{p} / p$ and $y^{q} / q$ with $1 / p+1 / q=1$ However, if he were to name it today, i.e. in 1977, he explained in the letter, he would probably choose the name 'parabolic polarity' because of the analogy with polarity between convex sets (KISELMAN 2019, p. 10).
} 


$$
y=\sum_{i=1}^{n} x_{i} \xi_{i}-\varphi(\xi)
$$

In his lecture notes from the course he gave at Princeton, Fenchel introduced the conjugate functions and derived the first duality result in nonlinear programming based on this notion of conjugacy.

He considered a closed convex function $f(x)$ defined on a convex set $C$ in $\mathbb{R}^{n}$, and a closed concave function $g(x)$ defined on a convex set $D$ in $\mathbb{R}^{n}$. To a concave function, a conjugate function can be derived similar to how he did it for convex functions, using infimum instead of supremum in the definition of the conjugate function. He used the symbols $\varphi: \Gamma \rightarrow \mathbb{R}$, and $\psi: \Delta \rightarrow \mathbb{R}$ for the conjugate functions for $f$ and $g$ respectively. With this notation, he posed two problems:

\footnotetext{
"Problem I: To find a point $x^{0}$ in $C \cap D$ such that $g(x)-f(x)$ as a function in $C \cap D$ has a maximum at $x^{0} . "$ (FENCHEL 1953, p. 105)

"Problem II: To find a point $\xi^{0}$ in $\Gamma \cap \Delta$ such that $\varphi(\xi)-\psi(\xi)$ as a function in $\Gamma \cap \Delta$ has a minimum at $\xi^{0}$." (FENCHEL 1953, p. 105)
}

Geometrically, if $g(x)-f(x) \geq 0$ in $C \cap D$ Problem I corresponds to finding the maximum vertical distance between the two graphs $g(x)$ and $f(x)$ in $C \cap D$ and there is an analogue geometrically interpretation of Problem II. As noted by Fenchel, if $f(x) \equiv 0$ in $C$, the first problem is a programming problem: to maximize $g(x)$ subject to the constraints $x \in C$.

Fenchel (1953, p. 109) proved that if $C$ and $D$ (and $\Gamma$ and $\Delta$ ) have points in common which are relative interior ${ }^{10}$ to both sets, the two problems are connected in the sense that the maximum of Problem I equals the minimum of Problem II, i.e.:

$$
\max _{x \in C \cap D}(g(x)-f(x))=\min _{\xi \in \Gamma \cap \Delta}(\varphi(\xi)-\psi(\xi)) .
$$

This is the first duality theorem for nonlinear programming. It is called 'Fenchel duality' and Fenchel is quite famous for this result in optimization theory.

\section{Conclusion}

The study presented in this paper of episodes of Fenchel's academic life from a perspective of the Second World War, shows aspects of how the War and mathematics interacted both with respect to his life conditions and in some of his mathematical work. As such, this study contributes to our understanding of how time and mathematics interfere.

The mathematical community at large played a role in helping German mathematicians to set up life in countries outside of Germany where they could continue their mathematical work. Harald Bohr played a decisive role in helping Jewish mathematicians, especially from

\footnotetext{
${ }^{10}$ In the lecture notes, he defined a point to be a relative interior point of a set $M$ if it is interior to $M$ relative to the topology of the smallest flat containing M. (FENCHEL 1953, p. 39)
} 
Göttingen, to establish life elsewhere, and in particular, he arranged for Werner Fenchel to come to Denmark, and helped him to establish a mathematical career. ${ }^{11}$

The way the military-university complex was organized in the USA and the military funding of academic science in the post war period had a huge influence on various areas of mathematics. New sub-disciplines were investigated and developed in the post war period, mathematical programming being one of them. Fenchel was an expert on convexity theory not the least due to Neugebauer and Bonnesen. Because of that, and because of the ONR financed project in Princeton, he came to work on mathematical programming and introduced his conjugate convex functions - his duality - into this field. Hereby he derived the first duality theorem of mathematical programming - a military born problem that moved into academia and became subject of academic research, due to the militaryuniversity complex in the USA in general and the ONR funding in particular, as direct consequences of the Second World War.

\section{References}

DANTZIG, George B. and Wood, M. K. Programming of Interdependent Activities, I General Discussion. Econometrica, 17, p.193-199, 1949.

FENCHEL, W. On Conjugate Convex Functions. Canadian Journal of Mathematics, 1, p. 73$77,1949$.

FENCHEL, W. Convex Cones, Sets, and Functions. Lecture Notes, Department of Mathematics, Princeton University, 1953.

FENCHEL, W. Interview in a newspaper. Box 1. (no date)

FENCHEL, W. Minder fra studietiden. Box1, 1975.

FENCHEL, W. Interview with Werner Fenchel. The Royal Academy of Sciences, Denmark, August 19, 1986. (Conducted by Gert Kjærgård Pedersne, Transcribed by Jørn Børling Olsson. (My translation into English)

JENSEN, B. E. Historie - livsverden og fag (History-lifeworld and discipline). Copenhagen: Gyldendal, 2003.

KISELMAN C. O. Werner Fenchel, a pioneer in convexity theory and a migrant scientist. Nordisk matematisk tidskrift, 61 (2-4), p. 133-152, 2019.

KJELDSEN, T. H. A Contextualized Historical Analysis of the Kuhn-Tucker Theorem in Nonlinear Programming: The Impact of World War II. Historia Mathematica, 27, p. 331-361, 2000.

KJELDSEN, T. H. Uses of History for the Learning of and about Mathematics: Towards a theoretical framework for integrating history of mathematics in mathematics education. In Proceedings of the International Conference on History and Pedagogy of Mathematics (HPM): 1-21. The HPM Satellite Meeting of ICME-12, July 16-20, Daejeon, Korea, 2012.

\footnotetext{
${ }^{11}$ For more information on the role of Harald Bohr, see Ramskov (1995).
} 
KJELDSEN, T. H. A Multiple Perspective Approach to History of Mathematics: Mathematical Programming and Rashevsky's Early Development of Mathematical Biology in the Twentieth Century. In Gert Schubring (Ed.) Interfaces between Mathematical Practices and Mathematical Education. Springer, 2019. p. 143-167, 2019.

KOOPMANS, T. C. (Ed.) Activity Analysis of Production and Allocation. Cowles Commission Monograph, 13, New York: Wiley, 1951.

KUHN, H. W. and TUCKER, A. W. Nonlinear Programming. Proceedings of the Second Berkeley Symposium on Mathematical Statistics and Probability, p. 481-492, 1950.

OLD, B. S. The Evolution of the Office of Naval Research. Physics Today, 14, p. 30-35, 1961.

OWENS, L. Mathematicians at War: Warren Weaver and the Applied Mathematics Panel, 1942-1945. In The History of Modern Mathematics, II: Institutions and Applications, eds. David Rowe and John McCleary, 287-305. San Diego: Academic Press, Inc., 1989.

RAMSKOV, K. Matematikeren Harald Bohr (The Mathematician Harld Bohr). Institut for de eksakte videnskabers historie, Det naturvidenskabelige Fakultet, Aarhus Universitet. Ph.D. thesis (in Danish), 1995.

REES, M. S. Mathematics and the Government: The Post-War Years as Augury of the Future. In The Bicentennial Tribute to American Mathematics, 1776-1976, TARWATER, D. (ed.). Buffalo, NY: The Mathematical Association of America, p. 101-116, 1977a.

REES, M. S. Early years of the Mathematics Program at ONR. Naval Research Reviews, 30: p. 22-29, $1977 \mathrm{~b}$.

ROCKAFELLAR, R. T. Convex Analysis. Princeton. New Jersey: Princeton University Press, 1970.

SAPOLSKY, H. M. Academic Science and the Military: The Years Since the Second World War. In REINGOLD, N. (Ed.). The Sciences in the American Context: New Perspectives.

Washington, D. C.: Smithsonian Institution Press, p. 379-399, 1979.

SCHWEBER, S. S. The Mutual Embrace of Science and the Military: ONR and the Growth of Physics in the United States after World War II. In E. MENDELSOHN, M. R. SMITH and P. WEINGART (eds.) Science, Technology and the Military. Dordrecht, The Netherlands: Kluwer Academic Publishers, p. 101-116, 1989.

ZACHARY, P. G. Endless Frontier: Vannevar Bush, Engineer of the American Century. New York: The Free Press, 1997. 